\title{
Relation between electromyography and anal manometry of the external anal sphincter
}

\author{
M Sørensen, T Tetzschner, O Ø Rasmussen, J Christiansen
}

\begin{abstract}
Thirteen patients with faecal incontinence and 26 control subjects were studied to investigate whether a quantitative electromyographic (EMG) signal could be correlated to anal manometry. Three different electrodes were used - a concentric needle electrode, a disposable sponge electrode, and a hard anal plug electrode. The maximum amplitude of the EMG recording was used as a quantitative parameter. Linear regression showed significant correlation between EMG and anal manometry with the sponge electrode, both at rest and during squeeze. Significant correlation was also found with the concentric needle electrode during squeeze but not at rest. No correlation was found with the hard anal plug electrode either during squeeze or at rest. Reproducibility studies using the sponge electrode showed acceptable day to day variation. In conclusion, quantitative EMG recordings from a disposable sponge electrode placed in the anal canal correlate well to anal manometry and may be used for assessment of sphincter function, but the hard anal plug electrode cannot be recommended.
\end{abstract}

Conventional electromyography (EMG) of the external anal sphincter has mainly been used to 'map' sphincter lesions in traumatic incontinence, ${ }^{1}$ but the specific diagnosis of nerve damage and reinnervation of the muscle fibres of the external sphincter requires the more sophisticated technique of single fibre EMG. ${ }^{2}$ Quantitation of the EMG signal from the external anal sphincter by measurement of the maximum amplitude is not a commonly performed investigation in patients with faecal incontinence. Conventional EMG is easy to use routinely, however, and provides considerable information about the state of the sphincter muscles. The aim of this study was to investigate the value of EMG quantitation with different electrodes and to correlate the maximum amplitudes of the EMG signal to anal pressures in patients with faecal incontinence and healthy subjects.

Department of surgery D, Glostrup Hospital,

University of

Copenhagen, Denmark

M Sørensen

T Tetzschner

O Ø Rasmussen

J Christiansen

Correspondence to:

Dr J Christiansen,

Department of surgery $D$,

Glostrup Hospital, University

of Copenhagen, Denmark.

Accepted for publication

29 October 1990
SUBJECTS

Thirteen women with faecal incontinence, median age 64 years (range 37-87), were studied. Eleven patients had idiopathic faecal incontinence and two had incontinence because of neurological disease (stenosis of the lumbar spine and prolapse of an intervertebral disc). Twenty six control subjects with normal anal function
(14 women and 12 men, median age 45 , range 24-76 years) were studied for comparison.

\section{ANAL MANOMETRY}

Investigations were performed with the patients in the left lateral position with knees and hips flexed. Maximum resting and maximum squeeze pressures were measured with a low compliance open ended perfused polyvinyl catheter connected to a strain gauge and displayed on a chart recorder. The details of this technique have been described previously. ${ }^{3}$

\section{ELECTROMYOGRAPHY OF THE EXTERNAL ANAL} SPHINCTER

Investigations were performed with the patients in the left lateral position. Three different electrodes were used as follows:

(1) A disposable sponge electrode, Dantec 13L81 (Fig 1), consisting of two pick up plates each $28 \mathrm{~mm}^{2}$ mounted on a sponge $40 \mathrm{~mm}$ long with a diameter of $25 \mathrm{~mm}$, the sponge being compressible to a diameter of $4 \mathrm{~mm}$. The electrode was placed just inside the anal verge with the pick up plates at 3 and 9 o'clock.

(2) A hard anal plug electrode, Dantec 13K78/ 79 (Fig 1) also placed in the anal canal. ${ }^{4}$

(3) A concentric needle electrode, Dantec 13L58, inserted into the external anal sphincter,

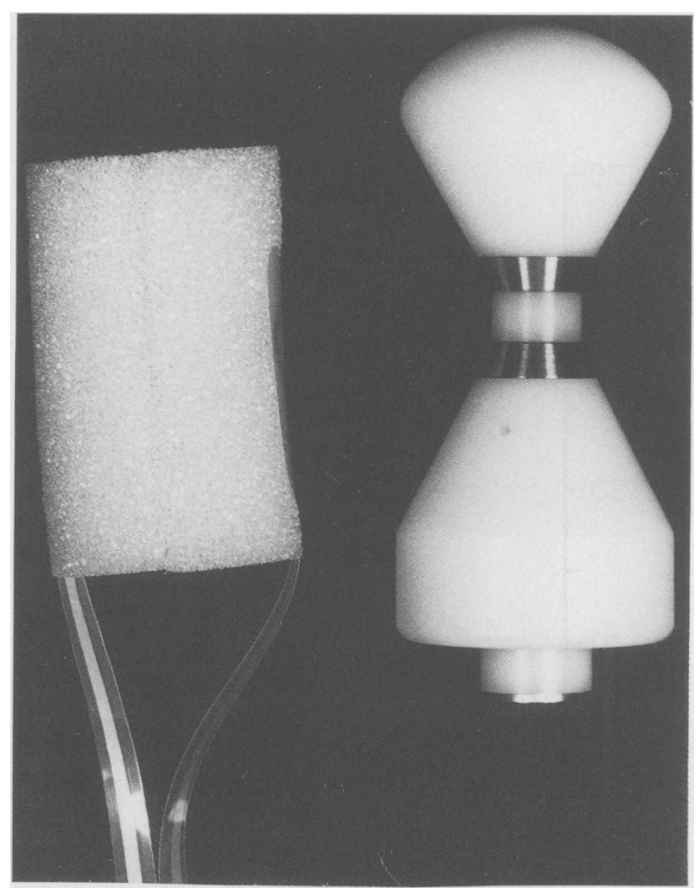

Figure 1: The sponge electrode and the hard anal plug electrode. 
Recrpat

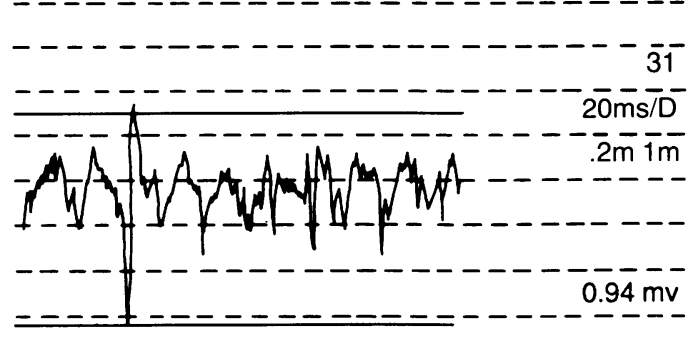

Figure 2: Electromyographic recording from the external anal sphincter with a concentric needle electrode. The two horizontal lines are adjusted so that the maximum amplitude of an unbroken sharp wave is measured.

\section{Sponge electrode}
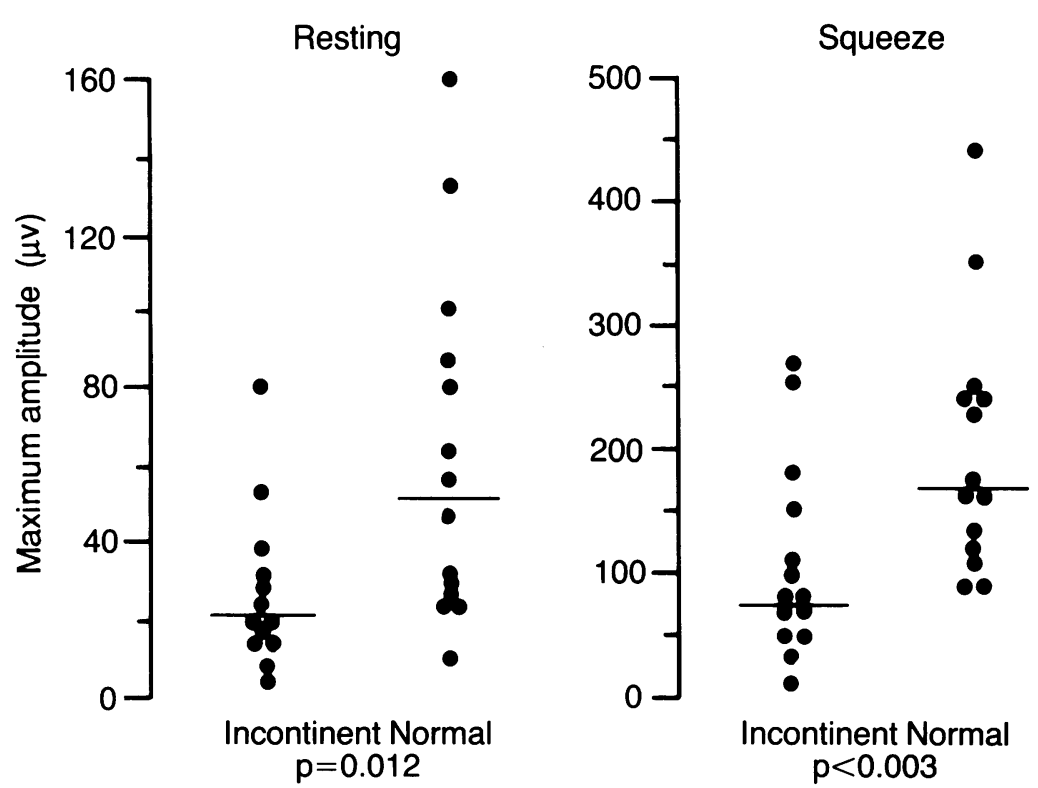

Figure 3: The maximum amplitudes with the sponge electrode at rest and during squeeze in patients with faecal incontinence and control subjects.

\section{Hard anal plug electrode}
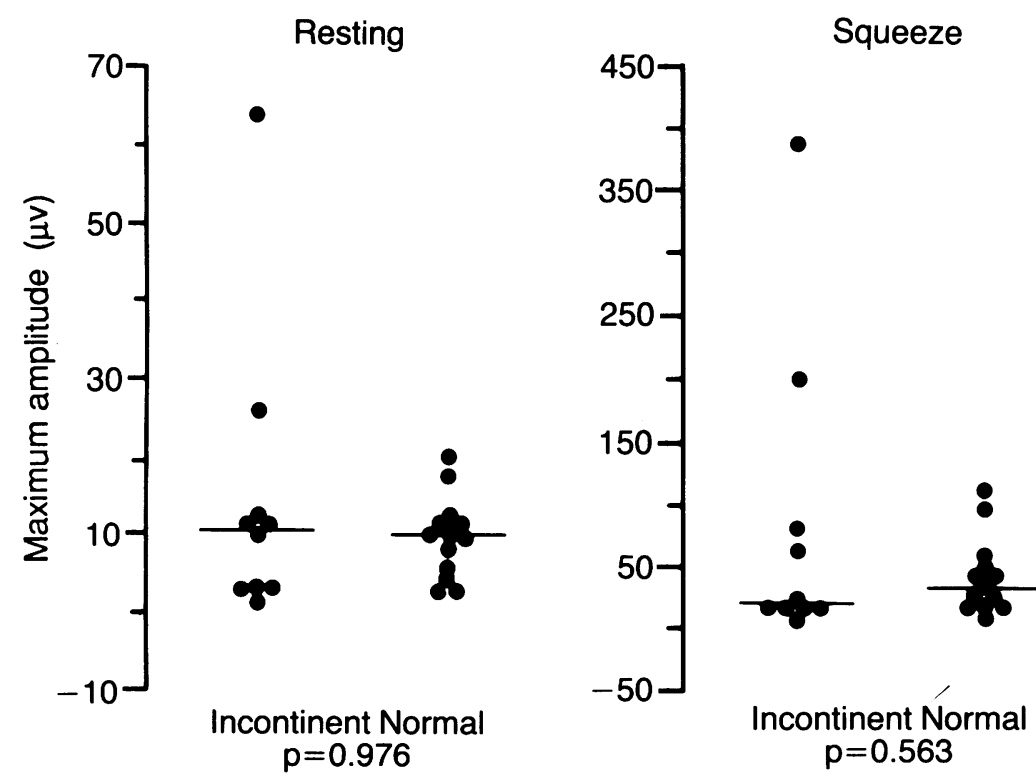

Figure 4: The maximum amplitudes with the hard anal plug electrode at rest and during squeeze in patients with faecal incontinence and control subjects. the position of the electrode being secured by digital examination and by a sound signal from the EMG apparatus. EMG with the needle electrode was only performed in the control subjects.

The EMG signals were recorded on a Neuromatic $2000 \mathrm{M} / \mathrm{C}$ EMG recorder (Dantec), filter settings $10 \mathrm{kHz}$ and $2 \mathrm{~Hz}$. The maximum amplitude of an unbroken sharp wave at rest and during squeeze was measured (Fig 2).

The electrode was left in situ for two minutes before measurement began to allow the external anal sphincter to adapt to its presence. To ensure effective contact, both the sponge electrode and the hard anal plug electrode were lubricated with gel before being placed in the anal canal. Day to day variation in results was studied with the sponge electrode by two measurements on different days.

\section{STATISTICAL ANALYSIS}

Differences were analysed by the MannWhitney U test for unpaired data. Only women were included in this analysis because the group of incontinent patients were all women. The intercept and correlation coefficients of the regression line were calculated by Pearson's parametric correlation analysis and all patients and control subjects were included in this analysis. Day to day variation was evaluated by plotting data as described by Bland and Altman. ${ }^{5}$

\section{Results}

\section{ANAL MANOMETRY}

The results of anal manometry in the two groups of patients are shown in the Table. Patients with faecal incontinence had significantly lower anal resting and squeeze pressures than the control subjects $(\mathrm{p}<0 \cdot 001)$.

\section{ANAL ELECTROMYOGRAPHY}

Figure 3 shows the distribution of the maximum amplitudes for the sponge electrode in women. Patients with faecal incontinence had lower maximum EMG amplitudes at rest $(p=0 \cdot 012)$ and during squeeze $(p<0.003)$. No difference could be shown for the hard anal plug electrode (Fig 4).

Figures 5 and 6 show the regression line and $95 \%$ confidence intervals between maximum

Anal manometry and electromyography $(E M G)$ in women with faecal incontinence and control subjects. (Values median (range).)

\begin{tabular}{lcc}
\hline & $\begin{array}{l}\text { Incontinent } \\
(n=13)\end{array}$ & $\begin{array}{l}\text { Control } \\
\text { (women }) \\
(n=14)\end{array}$ \\
\hline Anal manometry & & \\
Resting pressure (mm Hg) & $37(19-80)$ & $72(45-121) \dagger$ \\
Squeeze pressure (mm Hg) & $67(23-124)$ & $130(64-236) \dagger$ \\
Anal EMG (disposable sponge electrode) & $21(5-80)$ & $51(10-160)^{\star}$ \\
Resting(V) & $76(9-252)$ & $167(88-440)^{\star}$ \\
Squeeze (V) & $10(2-64)$ & $10(3-20)$ \\
Anal EMG (hard anal plug electrode) & $18(6-384)$ & $27(12-110)$ \\
Resting (V) & $1 \mathrm{~V})$ &
\end{tabular}

${ }^{\star} \mathrm{p}<0.03 ; \mathrm{tp}<0 \cdot 001$ 


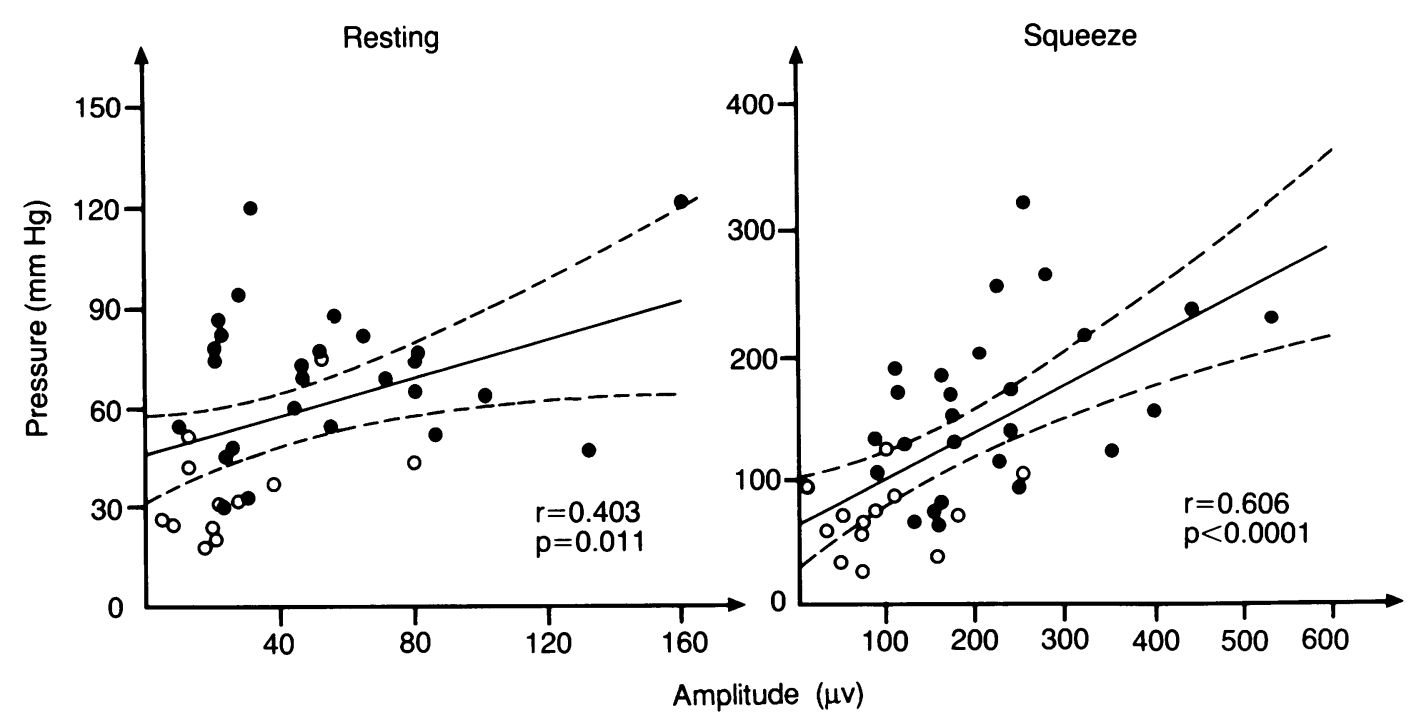

Figure 5: The regression line with $95 \%$ confidence intervals between anal manometry and anal electromyography $(E M G)$ with the sponge electrode at rest and during squeeze. Open circles=patients with faecal incontinence; closed circles=control subjects.

EMG amplitudes and maximum anal pressures at rest and during squeeze with the sponge electrode and the concentric needle electrode. The correlation coefficient at rest for the sponge electrode was $\mathrm{r}=0.403(\mathrm{p}=0.011)$ and during squeeze it was $r=0.606(p=0.00004)$. With the concentric needle electrode, the correlation coefficient at rest was $\mathrm{r}=0.080(\mathrm{p}=0.740)$ and during squeeze it was $r=0.541(p<0.02)$. No correlation was found with the hard anal plug electrode (Fig 7).

\section{DAY TO DAY VARIATION}

Figure 8 shows the Bland and Altman plots for the sponge electrode when day to day variation was tested in nine subjects. No systematic trend in the measurements was found.

\section{Discussion}

The results of this study show that quantitative EMG measurements of the external anal sphincter may be correlated to anal pressures, both at rest and during squeeze, when the EMG signal is recorded with the sponge electrode. Not surprisingly, the highest correlation coefficient was found during squeeze, where the external anal sphincter is responsible for most of the pressure. At rest, the internal anal sphincter is probably responsible for $40-60 \%$ of anal canal pressure,${ }^{67}$ indicating that any strong correlation between anal pressure and the EMG of the external sphincter cannot be expected.

When EMG is quantitated, as in this study, the maximum amplitude reflects the summation of action potentials in muscle fibres near the electrode. During squeeze, more muscle fibres

\section{Concentric needle electrode}

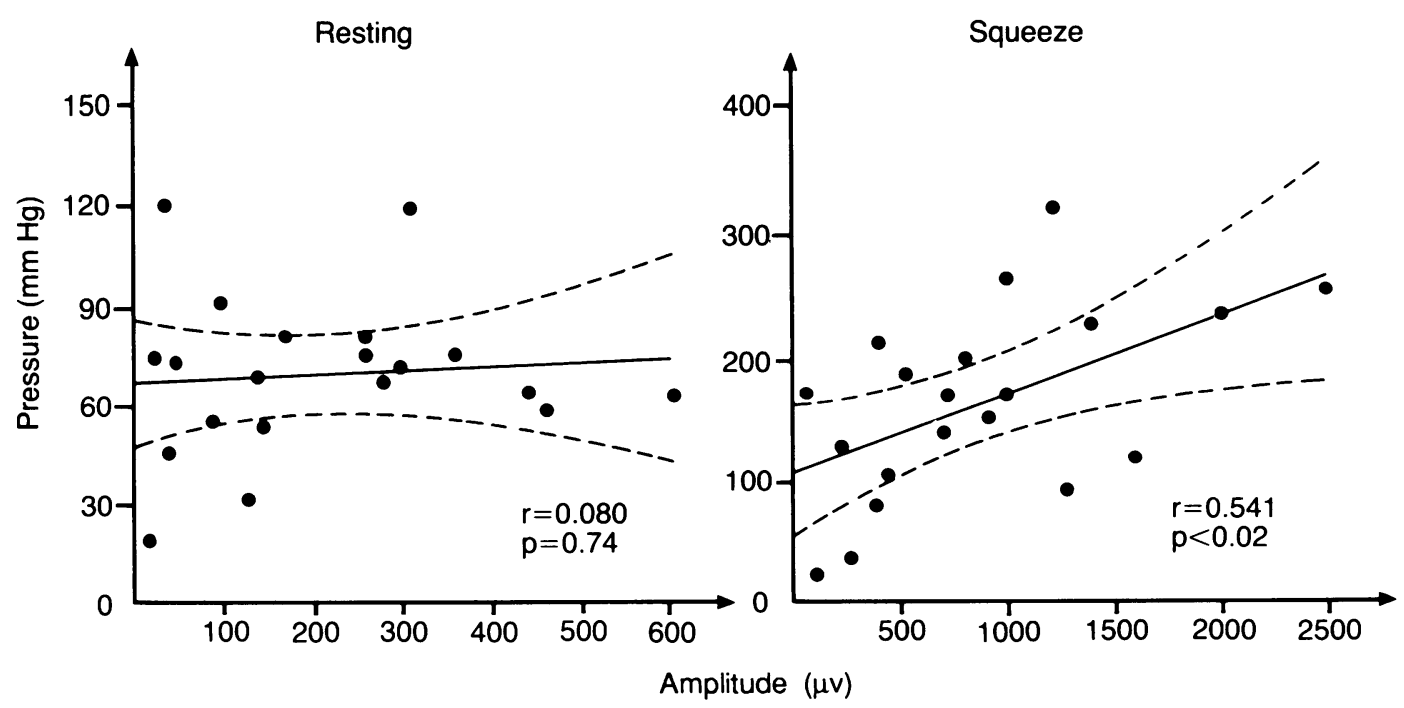

Figure 6: The regression line with 95\% confidence intervals between anal manometry and electromyography (EMG) from the external anal sphincter using the concentric needle electrode. Closed circles $=$ control subjects. 


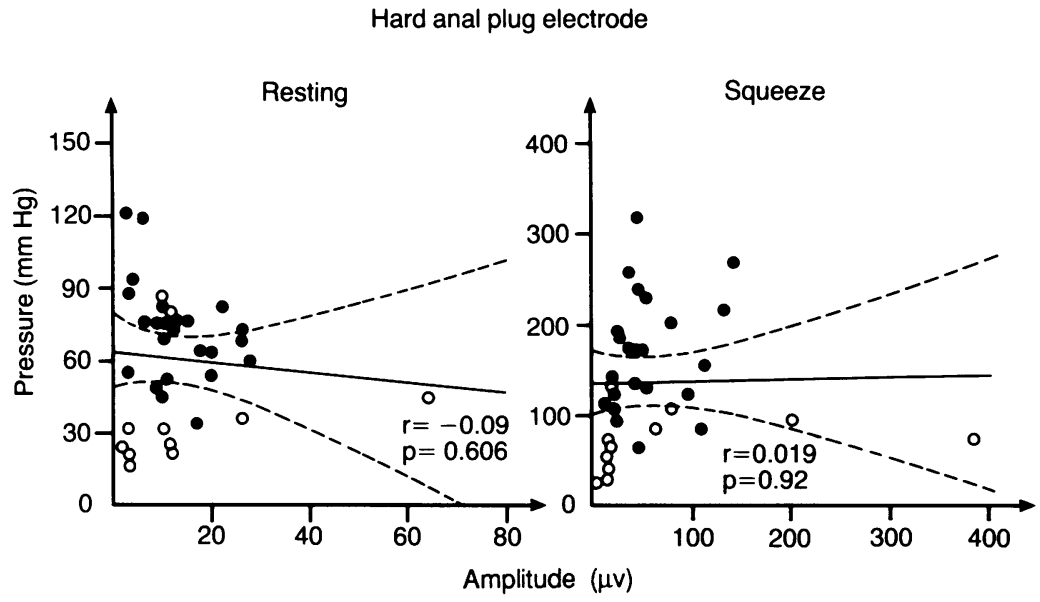

Figure 7: The regression line with $95 \%$ confidence intervals between anal manometry and anal electromyography $(E M G)$ using the hard anal plug electrode. Open circles=patients with faecal incontinence; closed circles $=$ control subjects.

measured with the sponge electrode. This is probably because the hard anal plug has less direct contact with the anal mucosa, resulting in an unfavourable signal/noise relation, which probably explains the poor correlation between anal manometry and EMG.

Study of day to day variation using the sponge electrode showed that reproducibility was acceptable. Day to day variation was not studied with the needle electrode and the hard anal plug electrode because of the discomfort these electrodes cause the subjects.

In conclusion, we found that the disposable sponge electrode is currently the best EMG electrode for routine use. In addition to the good correlation to anal manometry results, both at rest and during squeeze, the electrode is more comfortable for the patient and no cleaning sterilisation, or maintenance are needed. The

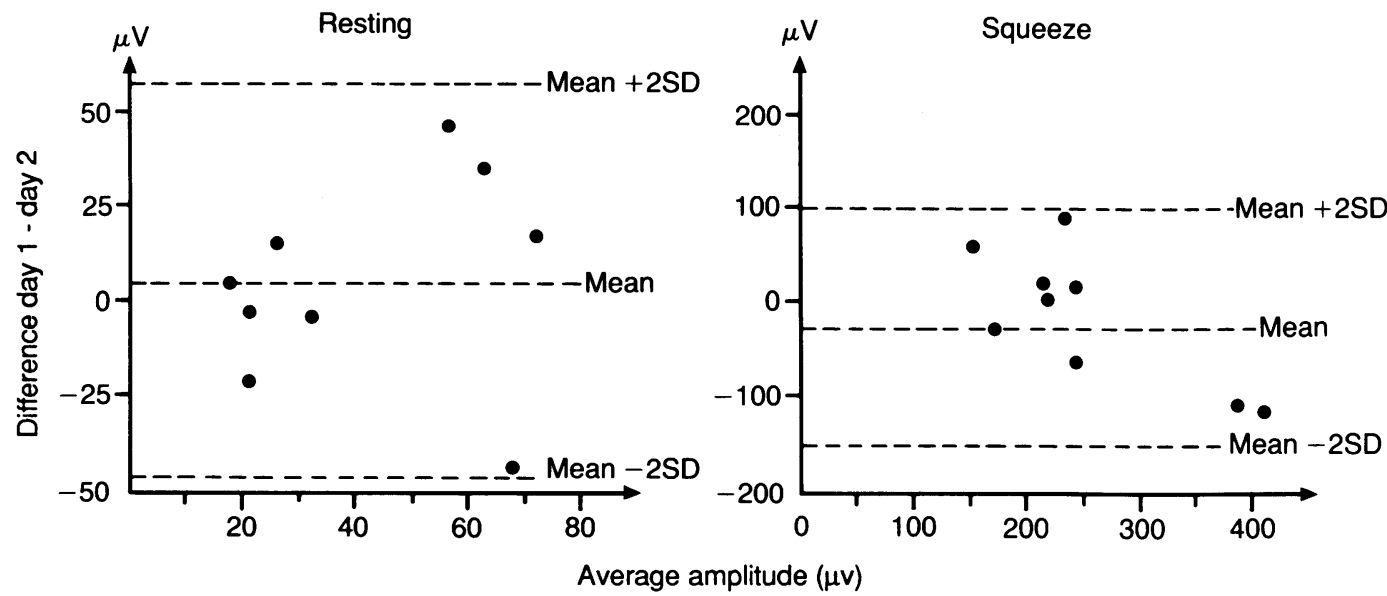

Figure 8: The day to day variation in measurements with the sponge electrode at rest and during squeeze (Bland and Altman plot)

are active, thus increasing the amplitude. The more active the muscle fibres, the higher the pressure.

With the concentric needle electrode, the EMG could be correlated to the squeeze pressure only, even though the needle electrode records signals with greater amplitude. The reason for this discrepancy is probably that the sponge electrode records action potentials from a large number of motor units and is therefore more likely to reflect the resulting pressure, while the concentric needle electrode picks up only the EMG signals from the adjacent 20-30 motor units within a radius of $1 \mathrm{~mm},{ }^{8}$ which may not be representative of the entire muscle. Also, only a few of these fibres are active at rest so that summation of action potentials is less likely to occur. Because of this the position of the needle becomes a key variable that weakens the correlation to the anal pressure.

The amplitude of the EMG signal measured with the hard anal plug is much less than that concentric needle electrode should not be used for routine examination, but is necessary for EMG mapping of the external sphincter. Use of the hard anal plug electrode cannot be recommended.

This study was kindly supported by Smith, Kline and French.

1 Swash $M$. New concepts in incontinence. $B M 71985 ; 290: 4-5$. 2 Neill ME, Swash $M$. Increased motor unit fibre density in the external anal shincter muscle in ano-rectal incontinence: single fibre EMG study. $\mathcal{F}$ Neurol Neurosurg Psychiaty 1980; 43: 343-7.

3 Petersen IK, Christiansen J. A study of the physiological variation in anal manometry. Br f Surg 1989; 76: 69-71.

4 Nielsen KK, Kristensen ES, Qvist N, Jensen KM-E, Krarup T, Pedersen D. A comparative study of various electrodes in T, Pedersen D. A comparative study of various electrodes in
electromyography of striated urethral and anal sphincter in electromyography of striated urethral
children. Br J Urol 1985; 57:557-9.

5 Bland JM, Altman DG. Statistical methods for assessing agreement between two methods of clinical measurement. Lancet 1986; i: 307-10.

6 Wunderlich M, Tekely B, Schiessel R. Sphincterfunktion nach coloanaler anastomose. Langenbecks Arch Chir 1986; 367 259-69.

7 Lestar B, Penninckx F, Kerremans R. The composition of anal basal pressure. Int $\mathcal{F}$ Colorect Dis 1989; 4: 118-22.

8 Staelberg E, Tronteli JV. Single fibre EMG. Old Woking: Mirvalle Press, 1979: 3-5. 